Document downloaded from:

http://hdl.handle.net/10251/141643

This paper must be cited as:

Torregrosa, AJ.; Broatch, A.; Gil, A.; Gómez-Soriano, J. (06-2). Numerical approach for assessing combustion noise in compression-ignited Diesel engines. Applied Acoustics. 135:91-100. https://doi.org/10.1016/j.apacoust.2018.02.006

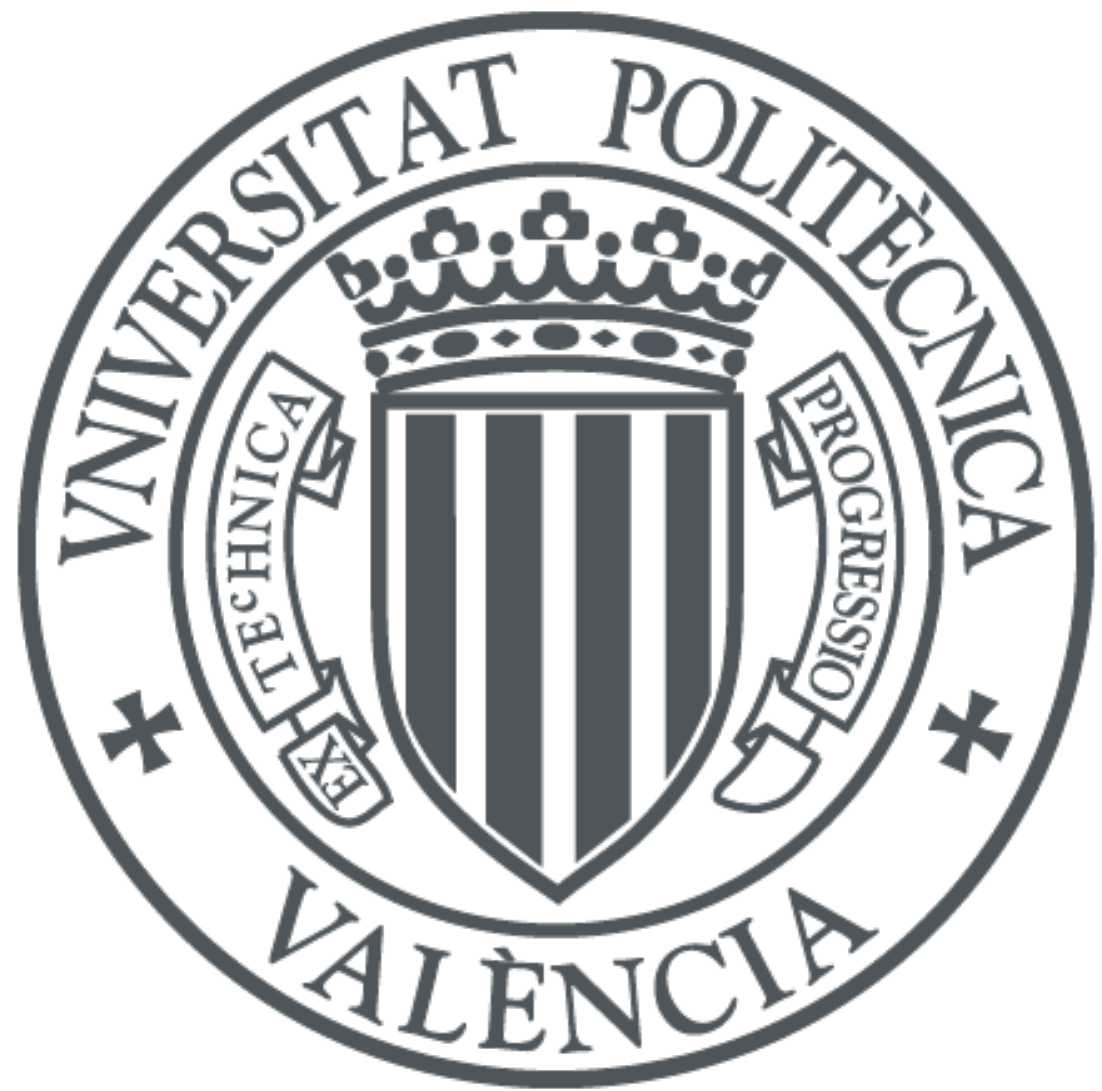

The final publication is available at

https://doi.org/10.1016/j.apacoust.2018.02.006

Copyright Elsevier

Additional Information 


\title{
Numerical approach for assessing combustion noise in compression-ignited Diesel engines
}

\author{
A. Torregrosa, A. Broatch*, A. Gil, J. Gomez-Soriano \\ ${ }^{a}$ CMT - Motores Térmicos, Universitat Politècnica de València, \\ Camino de Vera s/n, 46022 Valencia, Spain
}

\begin{abstract}
Diesel combustion noise has become a crucial aspect for the engine manufacturers due to its impact on human health and influence on the customer purchasing decision. The interaction of the pressure waves after mixture self-ignition induces cavity resonances inside the combustion chamber. This complex phenomenon produces high-frequency pressure oscillations, hence traditional in-cylinder measurements do not provide enough information to characterise the in-cylinder acoustic field. In this paper, a numerical methodology is proposed for assessing the Diesel combustion as a noise source and to overcome measurement limitations. An optimisation procedure is also presented in order to determine the numerical calculation parameters, boundary conditions definition and initialization. Results show that local flow conditions at the start of combustion have a strong influence on the acoustic response of the in-cylinder noise source. These particular conditions are only achievable by the proposed methodology which considers entire engine cycle simulations with the complete cylinder domain. Therefore, traditional Computational Fluid Dynamic (CFD) approaches, such those used for predicting combustion stability or pollutant emissions, are not suitable for reproducing the physical mechanisms of noise generation and they cannot be used for acoustic purposes. The reliability of the proposed methodology to simulate the acoustic field accurately inside the combustion chamber has been validated by comparison with experiments.
\end{abstract}

Keywords: Combustion noise, Resonance, Diesel engines, CFD approach

\section{Introduction}

Noise is an often-overlooked source of environmental pollution that has been stated as a serious health hazard. Longterm exposure to noise can produce annoyance and deterioration of sleep quality, raising the risk of serious diseases such as permanent hearing loss and even hypertension. The seriousness of these disorders have promoted several studies focused on determining a safe threshold for the noise level. The human acoustic perception is very sensitive to the intensity and the frequency of the sound [1]. Hence, similar noise levels can affect differently if they are emitted at distinct frequency ranges $[2,3]$. Furthermore, the differences in subjective judgement of people increase the complexity of this matter. The main issue is therefore to determine how much noise a person can reasonably handle without consequences.

In the present society, where population density and human activities increase industry demands, transportation is the main cause of noise. In particular, road traffic is by far the biggest source of noise, ahead of other external sources such as aircraft, industry or railway noise [4]. Noise coming from road traffic is originated by the engine -engine noiseand by the interaction of the vehicle with the environment -aerodynamic and tyre noise. The impact of engine noise on

*Corresponding author. Tel.: +34 9638796 50, fax: +34 9638776 59, email: abroatch@mot.upv.es the overall vehicle noise varies with the type of engine, and it is highly linked with the combustion concept. While the contribution of the combustion noise is moderate in spark ignition (SI) engines, it significantly increases in compression ignition (CI) Diesel engines.

Since the early nineties, Diesel engines have become the leading power plant in Europe, especially on light-duty vehicles, due to their performance, driveability and lower fuel consumption. In view of the expected increase of road traffic, public institutions have been forced to control the noise emissions in Diesel-powered vehicles by limiting the engine noise level. Thus, engine manufacturers are focused on reducing the overall noise in Diesel engines to comply with future legislations, and on improving the sound quality perceived by the customer subjectively because of its influence on the purchasing decision $[5,6]$.

The ignition of a volume element with a reactive blend act as acoustic source by inducing pressure instabilities. These perturbations can be generated as a consequence of the combustion process itself and due to unsteady heat release. The contribution of both promoters is remarkably different depending on the application. While the combustion noise in aero-engines is mainly produced by heat release fluctuations due to the instabilities caused by flame dynamics $[7,8]$, in $\mathrm{CI}$ engines the sudden pressure rise generated by the mixture self-ignition and the following premixed combustion dis- 


\begin{tabular}{|c|c|c|}
\hline \multicolumn{3}{|c|}{ Nomenclature } \\
\hline \multicolumn{2}{|c|}{ List of symbols } & Sub- and Superscripts \\
\hline c & speed of sound $\left(m \cdot s^{-1}\right)$ & cyl related to cylinder \\
\hline$(\mathrm{d} p / \mathrm{d} t)^{\max }$ & maximum pressure time-derivative $\left(\mathrm{kPa} \cdot \mathrm{s}^{-1}\right)$ & norm normalized value \\
\hline $\mathrm{E}_{\text {res }}$ & resonance energy $\left(\mathrm{Pa}^{2} \cdot s\right)$ & ref related to reference cycle \\
\hline$f$ & frequency $(\mathrm{Hz})$ & related to resonance phenomena \\
\hline$n$ & engine speed $(r p m)$ & comb related to combustion event \\
\hline $\mathrm{p}_{\text {cyl }}$ & in-cylinder pressure $(\mathrm{MPa})$ & \\
\hline$t$ & time $(s)$ & \\
\hline$u$ & flux velocity $\left(m \cdot s^{-1}\right)$ & \\
\hline$x$ & cell size $(m)$ & \\
\hline$\epsilon_{r}$ & relative error (\%) & \\
\hline$\tau_{i}^{\text {spray }}$ & ignition delay between sprays $(\mu s)$ & \\
\hline
\end{tabular}

misses any other source contribution. Therefore, in CI Diesel engines, heat release fluctuations during the diffusion combustion stage do not significantly contribute to the acoustic response in a significant way.

Once the ignition occurs, the interaction of the pressure and mechanical forces generates the acoustic excitation. Pressure forces act directly on the cylinder surrounding surfaces and produce noise emission through the engine block vibration. An additional vibration source arises as a consequence of mechanical forces, which are induced by the pressure forces transmitted by moving elements in the cylinder, piston slap, clearances, friction and deformation $[9,10]$.

The sources described above are strongly dependent on the sudden pressure rise due to the premixed combustion, which is mainly dependent on the fuel-burning velocity, and hence by the rate of heat release (RoHR). Moreover, this velocity is controlled by the fuel injection rate, the EGR rate and in-cylinder flow velocity (i.e., swirl flow conditions). Current engines can control all of these parameters through flexible devices such as common rail injection systems or advanced ECU software among others. The presence of high frequency oscillations along the in-cylinder pressure evolution is another consequence of the combustion event. These oscillations are related to the unsteady process known as combustion chamber resonance [11]. The interaction and the reflection of the pressure waves produce oscillation patterns of the gas inside the combustion chamber, commonly known as modes of resonance. The natural frequency of these modes depends on the gas temperature and the combustion chamber geometry. Hence all axial (longitudinal) modes and the transversal (radial and azimuthal) ones of order higher than third have associated frequencies out of the human hearing range [12]. The amplitude of these pressure oscillations is related to the achieved pressure gradients and the relative position of the self-ignition zones in the combustion chamber [13]. The variation of the combustion chamber geometry, the gas temperature and the local conditions during the combustion event and for cycle-to-cycle makes the resonance in Diesel engines a complex phenomenon. This event needs to be taken into account because of the characteristic excitation frequency span, which is in the highly sensitive human perception range. Furthermore, Torregrosa et al. [14] and Payri el al. [15] have proven the impact of the resonance on the radiated engine noise level and on the sound quality, respectively.

Previous works [16] have evidenced the strong influence of the pressure transducer location on the recorded signals, especially in the high frequency range. The main cause is the difference in the oscillation amplitudes along the combustion chamber due to the gas oscillation modes. Therefore, traditional in-cylinder pressure measurements do not provide enough information to analyse the resonance phenomena in detail. Hence, researchers have adopted different approaches in order to reach this aim: while some authors use different pressure transducers along the combustion chamber [17], others tend to use CFD models to understand this phenomenon.

In line with the latter trend, the simulation of the turbulence is the main limiting factor for reproducing the flow field accurately. Direct Numerical Simulation (DNS) can achieve very accurate results but the prohibitive computational costs make it improper for real flow applications. Unsteady Reynolds Averaged Navier-Stokes (U-RANS) is the standard approach in most practical internal combustion engine (ICE) flows. The low computational time demanded has promoted its wide usage in the automotive industry. U-RANS methods assume that velocity variations around the mean value are small and due to turbulence [18]. These hypotheses only allow to address cyclic variations which are due to isotropic turbulence. Thus, anisotropic effects such as intermittency due to large scale in-cylinder flow or misfires, are not reproduced correctly. Large Eddy Simulation (LES) methods appear as a partial solution to overcome some limitations of U-RANS models. These techniques decompose the flow field into large and small scales. The large scales are solved exactly whereas the small ones are approached by several models $[19,20]$. Vermorel et al. [21] has proven the suitability of LES methods for simulating cycle-to-cycle pressure variations in a 4-valve SI engine.

As described above, the resonance phenomenon could be highly variable between consecutive engine cycles owing to its strong dependence on local flow conditions. Thus, the 

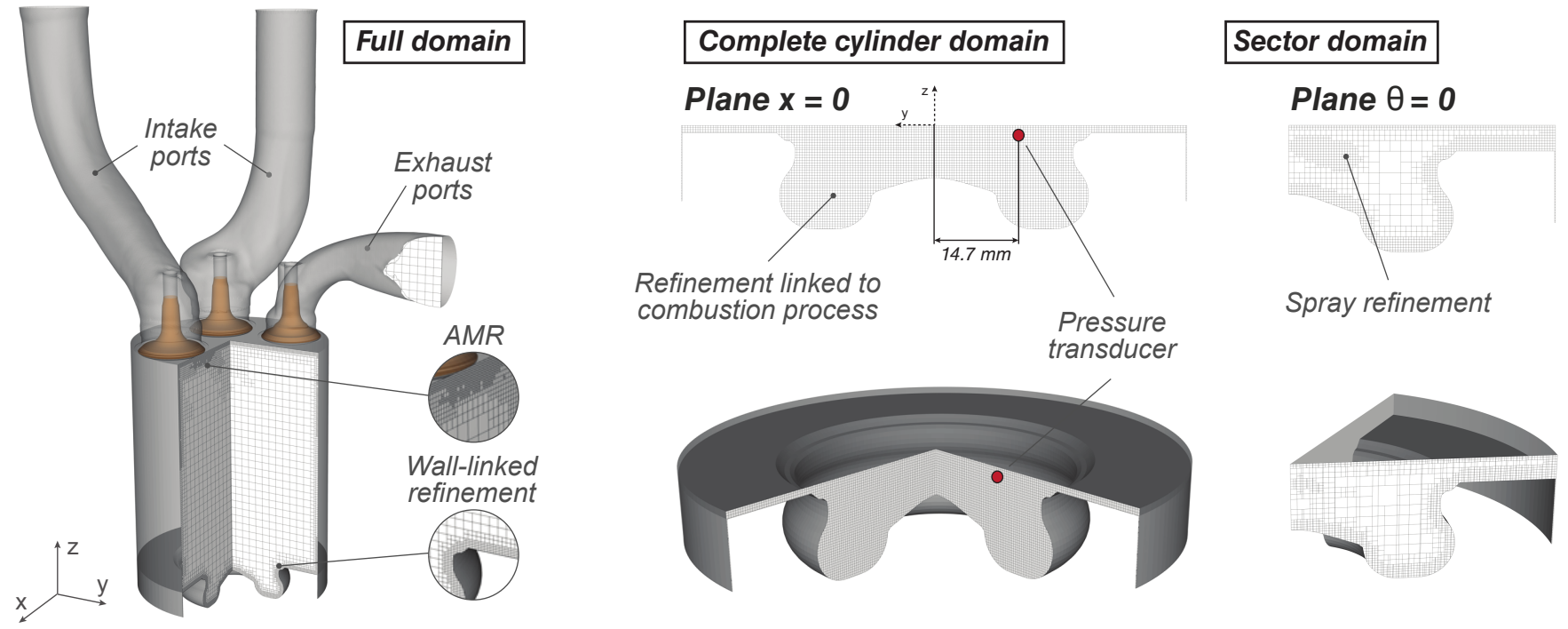

Figure 1: Computational domains and mesh characterization of the engine architecture

best option to analyse this phenomenon could be to use a LES approach in the CFD model. However, LES techniques are still being very demanding in terms of computational requirements for ICE applications. Additionally, previous works [22, $23,24]$ have evidenced the capacity of U-RANS to reproduce the high frequency pressure fluctuations. The predicted amplitude of these oscillations are similar to the averaged value of 100 measured cycles. These results have encouraged the authors to explore U-RANS modelling in order to define trends in the Diesel knock phenomenon for several operating conditions and design parameters [25].

Hence, the main objective of this research is to explore the capability of CFD for reproducing the combustion as a source of noise in a four-cylinder CI engine. In the next two sections, a description of the experimental set up and numerical tools are presented. The results obtained are discussed in Section 4. A validation of the numerical results is presented in Section 5. Finally, the conclusions obtained from this study are summarized in Section 6.

\section{Experimental setup}

\subsection{Engine and test cell characteristics}

The experimental characterisation has been carried out in a light-duty DI Diesel engine. This is a 1.61 , four-cylinder, turbo-charged engine equipped with a common rail injection system. All tests were performed with a 6-nozzle injector with hole diameters of $124 \mu \mathrm{m}$ and an included spray angle of $150^{\circ}$. The combustion chamber presents a conventional head design with a re-entrant bowl geometry (see Figure 1). This piston design provides a geometric compression ratio of 18. As a reference, the main specifications of the engine and the injector are presented in Table 1.
Table 1: Engine and injector specifications

\begin{tabular}{ll}
\hline Engine type & Direct-injection CI \\
\hline Number of cylinders [-] & 4 in line \\
Displacement $\left[\mathrm{cm}^{3}\right]$ & 1600 \\
Bore - Stroke $[\mathrm{mm}]$ & $75-88.3$ \\
Connecting rod length $[\mathrm{mm}]$ & 13.7 \\
Compression ratio [-] & $18: 1$ \\
Number of valves [-] & 2 intake and 2 exhaust \\
Injector nozzles & 6 \\
Nozzle holes diameter $[\mu \mathrm{m}]$ & 124 \\
Included spray angle $[\mathrm{deg}]$ & 150 \\
\hline
\end{tabular}

The gear box was assembled with the engine block in order to maintain the vibration patterns as close as possible to real operation. In addition, an asynchronous electric brake was directly coupled with the engine for controlling the engine speed. The latter was physically and acoustically isolated with sound damping panels so as to prevent possible interferences in the engine noise measurements. The test bench was installed inside of an anechoic chamber which offers free-field conditions for frequencies above $100 \mathrm{~Hz}$.

In-cylinder pressure was measured with a Kristler 6055Bsp piezoelectric transducer placed in the middle of the intake valves at the glow plug location (as can be seen in Figure 1). The noise radiated by the engine block was measured using a free-field microphone [14] and a Head Acoustics HMS III system [15]. The pressure and noise signals were sampled using a dedicated acquisition system and recorded during 50 consecutive engine cycles. All signals were also registered with a sample frequency of $50 \mathrm{kHz}$, ensuring a free-aliasing bandwidth similar to the human hearing domain $-20 \mathrm{~Hz}$ to $20 \mathrm{kHz}$ - according to de Nyquist criterion [26]. 
The rate of heat release, combustion phasing angles, maximum pressure time-derivative and maximum in-cylinder pressure were calculated from the in-cylinder pressure trace by means of the energy equation and some simplifications [27, 28]. The energy equation was solved assuming uniform pressure and temperature throughout the whole combustion chamber volume, giving the instantaneous mean temperature and the heat release.

\subsection{Combustion noise characterisation}

The characterisation of the combustion noise is based on the in-cylinder pressure decomposition proposed by Payri et al. [29]. According to this method, it is possible to identify three frequency bands in the pressure spectrum, each linked to one of the three engine cycle parts: compressionexpansion phase, combustion event and resonance phenomenon. This procedure also allows to identify which parameters are those most influential in each frequency band. Taking advantage of this information, subsequent investigations [14, 15] have found cause-effect relations between the source and both the objective and subjective effects of noise. Torregrosa et al. [14] have demonstrated the relation between the engine radiated noise or overall noise $(\mathrm{ON})$ and three indicators: one operation indicator which quantifies the effect of the engine speed, and two combustion indicators that represent the in-cylinder pressure rise and the high frequency gas oscillation inside the combustion chamber, respectively. Then, the overall noise can be obtained by

$$
\mathrm{ON}=C_{0}+C_{n} I_{n}+C_{1} I_{1}+C_{2} I_{2}
$$

where $C_{i}$ are coefficients dependent on the engine size and concept.

The operation indicator, $I_{n}$, depends on both the engine speed $(n)$ and the idle engine speed $\left(n_{\text {idle }}\right)$ as

$$
I_{n}=\log \left[\frac{n}{n_{\text {idle }}}\right]
$$

The first combustion indicator, $I_{1}$, which characterizes the sudden rise of pressure during the combustion event is defined as

$$
I_{1}=\frac{n}{n_{\text {idle }}}\left[\frac{(\mathrm{d} p / \mathrm{d} t)_{\mathrm{comb}}^{\max _{1}}+(\mathrm{d} p / \mathrm{d} t)_{\mathrm{comb}}^{\max _{2}}}{(\mathrm{~d} p / \mathrm{d} t)_{\mathrm{comp}}^{\max }}\right]
$$

where $(\mathrm{d} p / \mathrm{d} t)_{\text {comb }}^{\max _{1}}$ and $(\mathrm{d} p / \mathrm{d} t)_{\text {comb }}^{\max _{2}}$ are the two maximum values of the pressure time-derivative during the combustion, and $(\mathrm{d} p / \mathrm{d} t)_{\text {comp }}^{\max }$ is the highest peak of the pressure timederivative during the compression-expansion phase.

The last combustion indicator, $I_{2}$, is related to the resonance phenomena inside the combustion chamber and it is mathematically expressed as

$$
I_{2}=\log \left[E_{0} \frac{E_{\text {res }}}{E_{\text {comp }}}\right]
$$

Here $E_{0}$ is a convenient scaling factor and $E_{\text {res }}$ is the signal energy of the resonance pressure oscillations. As is usually considered in the in the field of signal processing, the latter is defined as

$$
\mathrm{E}_{\mathrm{res}}=\int_{\mathrm{IVC}}^{\mathrm{EVO}} p(t)_{\mathrm{res}}^{2} d t
$$

where $p(t)_{\text {res }}$ is the resonance pressure signal and intake valve closing (IVC) and exhaust valve opening (EVO) timings are the limits of the integral. This parameter characterises the global amplitude of the pressure oscillations due to the resonance phenomenon. Similar metrics such as peak pressure rise rate (PPRR) or ringing intensity (RI) are widely used in the literature for the same purpose. However, Shahlari et al. [30] has evidenced their weakness for characterising the resonance phenomenon when the combustion strategy, engine platform or operating conditions change. Thus, $\mathrm{E}_{\text {res }}$ offers better reliability to quantify the amplitude of the pressure oscillations because it is based on the pressure trace and not on indirect parameters [31]. Additionally, in some of the following studies, the resonance energy is normalized $\left(\mathrm{E}_{\mathrm{res}}^{\mathrm{norm}}\right)$ by a reference value $\mathrm{E}_{\text {comb }}$ defined as

$$
\begin{gathered}
\mathrm{E}_{\mathrm{res}}^{\mathrm{norm}}=\frac{\mathrm{E}_{\mathrm{res}}}{\mathrm{E}_{\mathrm{comb}}} \\
\mathrm{E}_{\mathrm{comb}}=\Delta p_{\mathrm{comb}}^{2} \Delta t
\end{gathered}
$$

where $\Delta p_{\text {comb }}$ is the maximum increase of the mean pressure due to the combustion event and $\Delta t$ is the time span in which this maximum is achieved. This normalisation procedure is necessary for comparison purposes, because in most cases it is not possible to reproduce exactly the same RoHR trace if any numerical parameter is varied.

Payri et al. [15] verified that the same two combustion indicators also correlate with the perceived sound quality of the combustion noise. The sound quality is quantified by a mark ranging from 0 to 10 which represents the customer satisfaction degree as

$$
\text { MARK }=10-C_{3} I_{1}-C_{4} I_{2}
$$

here $C_{i}$ are other coefficients dependent on the engine size and concept.

Moreover, in order to evaluate the source of combustion noise at each operation condition the overall pressure level, termed 'cylinder pressure level' (CPL), is estimated using the following expression:

$$
\mathrm{CPL}(\mathrm{dB})=10 \cdot \log \frac{P_{N}^{2}}{p_{0}^{2}}
$$

where $p_{0}=20 \mu P a$ and

$$
P_{N}=\frac{1}{N} \cdot \sum_{f=f_{1}}^{f_{N}} P(f)
$$


where $\mathrm{N}$ is the number of harmonics between $f_{1}$ and $f_{N}$, while $P(f)$ represents the Fast Fourier Transform of the pressure signal $(p(t))$.

Since the resonance phenomenon has been traditionally characterised by the amplitude of the excited oscillation modes, it is convenient to establish a notation showing the spatial pattern of each cavity mode. As a reference, Figure 2 presents the terminology used in this paper to designate acoustic modes in the combustion chamber [11].

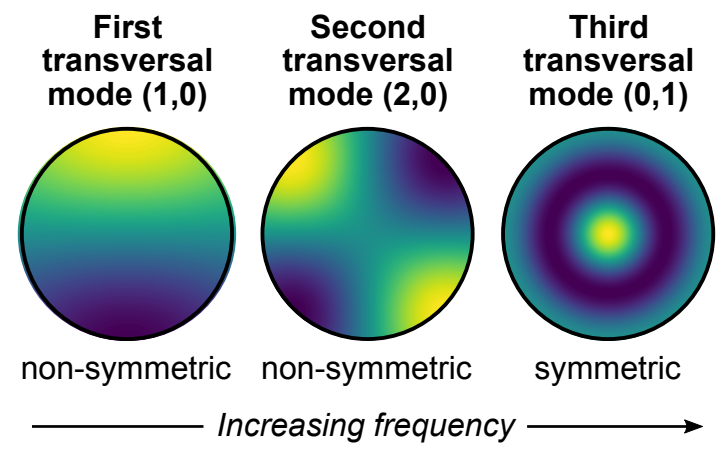

Figure 2: Cross-sectional views and notation of classical acoustic modes in combustion chambers [11].

Finally, the relative error between measured and CFD calculated pressure traces has been estimated as a function of crank angle $\left(\epsilon_{r}(\alpha)\right)$ in order to obtain the maximum relative error during the cycle $\left(\epsilon_{r}^{\max }\right)$. The relative error for an arbitrary variable $(\phi)$ is defined as

$$
\epsilon_{r}[\%]=\frac{\left|\phi_{\mathrm{CFD}}-\phi_{\exp }\right|}{\phi_{\exp }} \cdot 100
$$

\section{Numerical model setup}

The commercial CFD code CONVERGE, based on the finite volume method, was chosen to implement the numerical model. Figure 1 shows the three-dimensional domain which includes the complete cylinder geometry and intake-exhaust manifolds, allowing to perform full coupled open and closed cycle simulations. The whole domain was discretised in a structured grid of hexahedrons with a base cell size of $3 \mathrm{~mm}$. Several grid refinements were added to the original mesh size in order to improve the accuracy for simulating the reflection and interaction of the pressure waves within the domain. Three levels of grid refinement were included in the wall surrounding areas and along the whole cylinder when the combustion starts. Three supplementary levels of grid refinement were also activated in the spray zones to reproduce precisely the complex phenomena related to the chemical reactions and spray atomisation, break-up, coalescence, etc. In addition, the code used an adaptive mesh refinement algorithm (AMR) to increase the spatial resolution in areas where flow velocity and temperature variations are meaningful. The number of cells depended on the simulation parameters and varied among $1.5 \times 10^{6}$ cells at the Bottom Dead Center (BDC) and $0.5 \times 10^{6}$ at Top Dead Center (TDC).
The renormalization group (RNG) $k-\epsilon$ model [32] with estimated wall heat fluxes [33] was used to approximate the turbulent flow properties. The injection event was modelled by the standard Discrete Droplet Model (DDM) [34] whereas the spray atomisation and break-up are simulated by means of the Kelvin-Helmholtz Rayleigh-Taylor (KH-RT) model [35]. $\mathrm{N}$-heptane was chosen as a surrogate to predict the physical properties of diesel fuel. Concerning combustion event, the code approaches the detailed chemistry of the domain with a direct integration of the chemical reactions by means of the SAGE (detailed transient chemistry solver) solver. A chemical mechanism corresponding to a Primary Reference Fuel (PRF) blend of $n$-heptane and iso-octane was selected as a surrogate fuel. The iso-octane reactions were deactivated in order to predict and simulate the diesel ignition features. Moreover, the reaction mechanism for PRF oxidation was derived from the ECR-Multichem mechanism [36], characterizing the fuel chemistry with 42 species and 168 reactions.

The simulations encompass timings between IVC and EVO. However, some simulations were calculated during the entire cycle, among two consecutive EVO timings, in order to provide more realistic flow conditions during the combustion. The computational time was optimised with a dynamic time step strategy based on two different Courant number definitions. The time step was calculated by keeping the Courant number close to one and considering the cell size and a characteristic velocity. Both dimensionless parameters, flow and sonic Courant numbers, are defined as

$$
\begin{aligned}
& C_{u}=u \frac{\Delta t}{\triangle x} \\
& C_{c}=c \frac{\triangle t}{\triangle x}
\end{aligned}
$$

where $u$ is the flow velocity, $c$ is the speed of sound, $\Delta x$ is the cell size and $\Delta t$ is the time step. In this procedure, the flow velocity was taken as a characteristic velocity during the compression and injection phases, whereas the speed of sound was considered in the combustion phase in order to ensure an accurate prediction of the pressure oscillations.

Isothermal conditions were imposed at solid walls such as cylinder liner, piston surface, intake-exhaust manifolds, etc. Wall temperatures required for these boundaries were obtained by applying the lumped model proposed by Torregrosa et al. [37]. In full cycle simulations the inflow/outflow boundary conditions were implemented to impose the mean value of the experimental intake/exhaust signals (both temperature and pressure). The strong influence of the pressure transducer location on the pressure measurements, specifically in the high frequency range, has been proven in several research works $[16,38]$. Taking this into account, one monitor point was placed at the same location of the experimental pressure transducer, in order to compare the experimental and simulated pressure evolution. In addition, pressure traces were registered at a sampling frequency of $50 \mathrm{kHz}$ to provide enough free-aliasing bandwidth to cover the human range of hearing. 
Table 2: Parameters definition for studies and validation

\begin{tabular}{|c|c|c|c|c|c|c|}
\hline Study & Domain & Mesh size [mm] & Sonic Courant number [-] & Initial conditions & Injections [-] & Injector nozzles [-] \\
\hline Mesh independence & Complete cylinder & $2,2.5,3,3.5,4$ & 1 & Uniform & 1 & 1 \\
\hline Time step & Complete cylinder & 3 & $0.5,1,2,10,50$ & Uniform & 1 & 1 \\
\hline Auto-ignition location & Complete cylinder (simplified) & 3 & 1 & Uniform & 1 & 1 \\
\hline Domain & $60^{\circ}$ sector, $180^{\circ}$ sector, complete cylinder & 3 & 1 & Uniform & $\begin{array}{l}1 \\
1\end{array}$ & 6 \\
\hline Initial conditions & Complete cylinder, full & 3 & 1 & Uniform, GEP & 1 & 6 \\
\hline Validation & Full & 3 & 1 & GEP & 3 & 6 \\
\hline
\end{tabular}

The cluster used to perform all calculations is formed by 4 Fujitsu RX500 servers and 72 Fujitsu BX920 blades with 1280 cores. The return time for a complete cycle, 720 crank angle degrees (cad), was about $130 \mathrm{~h}$ when the process was distributed on 32 cores. In the same way, closed cycle simulations need about $60 \mathrm{~h}$ to perform the calculation.

\section{Model implementation}

In order to implement the CFD model, five studies were performed in order to evaluate the impact of several relevant parameters on the frequency content of the in-cylinder pressure. The first two studies were focused on establishing the optimum value of two calculation parameters, the mesh size and the time step. The third study can be considered as a preliminary validation procedure. It used the optimum calculation parameters, obtained from the two preceding studies, for reproducing results previously obtained by other authors $[16,13]$. The fourth evaluated the impact of assuming periodic hypothesis in the domain definition. The final study compared the results obtained by using different definitions of the initial conditions. Table 2 shows the complete information about the configuration parameters used for the referred studies.

The analysed parameters (base cell size, time step definition, self-ignition location, computational domain and initial conditions) were selected taking into account previous investigations [13] and preliminary studies.

\subsection{Mesh independence study}

One of the most critical aspects in a CFD simulation is to define a mesh that ensures an accurate solution while ensuring that the computational time remains under reasonable values. The code uses an internal algorithm to create a structured mesh based on hexhaedrons with a given base cell size. This procedure ensures high mesh quality but it does not supply an appropriate mesh size. Hence a mesh independence study is performed in this section in order to guarantee that the domain discretisation does not affect to the most relevant acoustic parameters.

The study has been made for the complete cylinder domain (see Figure 1) with a sonic Courant number close to one, uniform initial conditions (thermodynamics, turbulence and species) and with a one-nozzle injector which sets a single excitation source. Five different mesh sizes are defined with the base cell size parameter varying from 2 to $4 \mathrm{~mm}$. Figure 3 shows the results obtained in terms of frequency and amplitude of the pressure oscillations for a monitor placed at the same location of the pressure transducer. These results evidence no influence of the mesh size on the frequency of the three first modes of resonance [11]. However, a noticeable dispersion is observed in the amplitude of the transition frequencies between oscillation modes. The normalized energy of the resonance ( $E_{\text {res }}^{\text {norm }}$ ) shows the effect of this on the global amplitude of the resonance oscillations. In addition, it confirms that the global amplitude of the resonant oscillations does not change with meshes of base size close to 2.5 $\mathrm{mm}$. Nonetheless, considering the increase in computational cost, it was deemed sufficient to use a reference mesh size of $3 \mathrm{~mm}$ which yields less than $5 \%$ error in the amplitude of the pressure oscillation with respect to the mesh-independent solution.
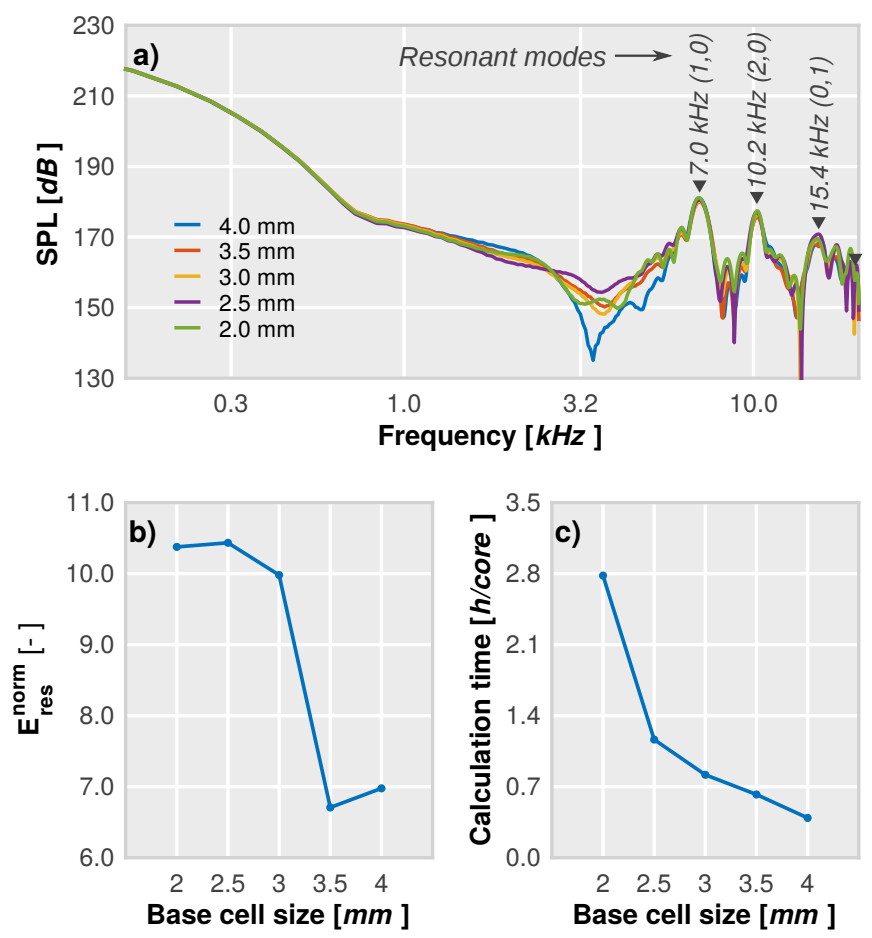

Figure 3: Results of the independence mesh study. a) Comparison of the pressure spectra traces, b) Differences in the global amplitude of the pressure oscillations, c) Computational costs of a single cycle simulation

\subsection{Time step definition}

As described in section 3, the CFD model uses the sonic Courant number to fix the calculation time step during the combustion event. This mathematical procedure establishes 

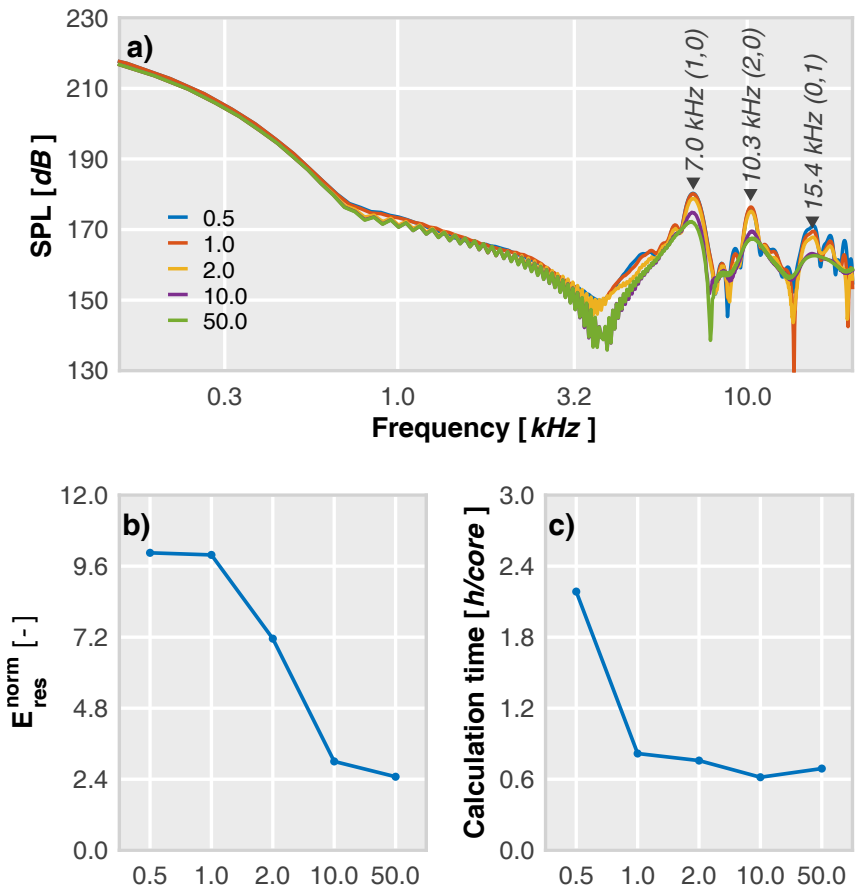
Sonic Courant number [-]

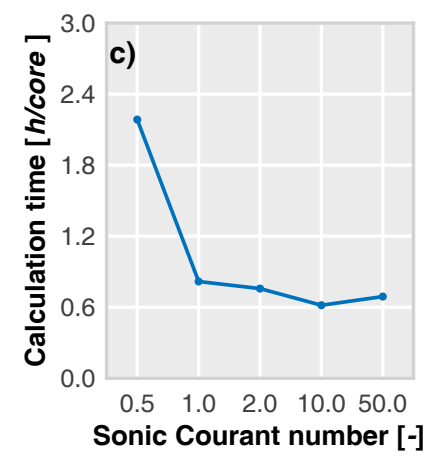

Figure 4: Results of the time step definition study. a) Comparison of the pressure spectra traces, b) Differences in the global amplitude of the pressure oscillations, c) Computational costs of a single cycle simulation

how many cells sweeps a pressure wave between two consecutive time steps of the calculation. Previous studies [22] have mentioned the relevance of this parameter in the in-cylinder pressure trace, specially in aeroacoustics. In this way, the following study analyses the impact of the time discretisation on the frequency response.

The study has been carried out in the complete cylinder domain with a base cell size of $3 \mathrm{~mm}$, uniform initial conditions and with a single excitation source (one-nozzle injector). The different time step definitions are determined by maintaining the sonic Courant number close to 50, 10, 2, 1 and 0.5 , respectively. The pressure spectra at a monitor placed in the transducer location are shown in Figure 4a, where significant amplitude differences are observed in the three main resonant modes. It can be seen that the pressure oscillations due to the resonance phenomenon are attenuated as the sonic Courant number increases. These trends are confirmed by the $\mathrm{E}_{\text {res }}^{\text {norm }}$ curve in Figure 4b: the global amplitude of the pressure oscillations drastically decreases for sonic Courant numbers between 5 and 50 and it reaches its maximum value for sonic Courant numbers below one. Thus, considering the calculation time increase shown in Figure $4 \mathrm{c}$ the optimum time step definition was fixed by a sonic Courant number close to one, assuring a suitable reproduction of the pressure wave interaction and reflection mechanisms.

\subsection{Auto-ignition location}

In the past, some authors $[11,12]$ studied the resonances inside ducts or chambers from the point of view of its effects in the frequency domain. One of their contribution was the ability to identify the frequencies of the oscillation modes through the solution of the wave equation for a circular cylinder

$$
f_{m, n}=\alpha_{m, n} \frac{c}{B}
$$

where the $f_{m, n}$ is the excitation frequency of the mode $(m, n)$, $\alpha_{m, n}$ is the oscillation mode coefficient for mode $(m, n), c$ is the mean speed of sound which mainly depends on the incylinder temperature, and $B$ is the cylinder bore. Torregrosa et al. [16] and Broatch et al. [13] showed the impact of the RoHR on the frequency content of in-cylinder pressure. They demonstrated how the amplitude of the resonant modes is amplified as the maximum RoHR increases. Moreover, they claim that the location of the self-ignition zones can influence the frequency content of the spectrum between two consecutive resonant modes and therefore, changing in a significant way the global amplitude of the pressure oscillations $\left(\mathrm{E}_{\mathrm{res}}\right)$. These studies were made by assuming no piston motion and they did not consider the effect of the expansion stroke on in-cylinder temperature. Hence, the aim of the present study is to reproduce the latter studies with a moving piston mesh and to examine the evolution of $\mathrm{E}_{\mathrm{res}}$.

In this study, it is imperative to reproduce an analogous RoHR profile as close as possible between simulations while the location of the self-ignition is varied by the injector position. Therefore, a simplified cylinder version, presented in Figure 5, of the complete cylinder domain is used to avoid possible spray-wall interactions which could influence the fuel energy release. In addition, an injector with only one nozzle is considered to easily control both the ignition location and energy release. The calculation parameters are presented in Table 2 and they follow the same considerations as viewed on the previous studies.

Two variations of a reference position were considered in both cylindrical coordinates (radial and axial). Therefore, the radial position of the injector was conveniently modified in Figs. $5 b$ and $5 c$ to change the location of the spray ignition. On the other hand, Figs. 5d and 5e display the results of modifying the ignition position along the axial coordinate of the cylinder. All these graphs show snapshots of RoHR contours at the middle spray plane and at the same percentile of the heat release $(10 \%$ of fuel burnt or CA10) that, in this case, almost coincide with the same crank angle since the RoHR is practically identical. Lastly, Figs. $5 \mathrm{f}$ and $5 \mathrm{~g}$ show how these modifications change the energy of resonance within the chamber.

Examination of the two latter graphs reveals the effect of varying the self-ignition location in the global amplitude of pressure oscillations along both cylindrical coordinates. The resonance energy rises as the combustion is moving towards the cylinder walls, increasing the global amplitude pressure 
a) Relative radial position:

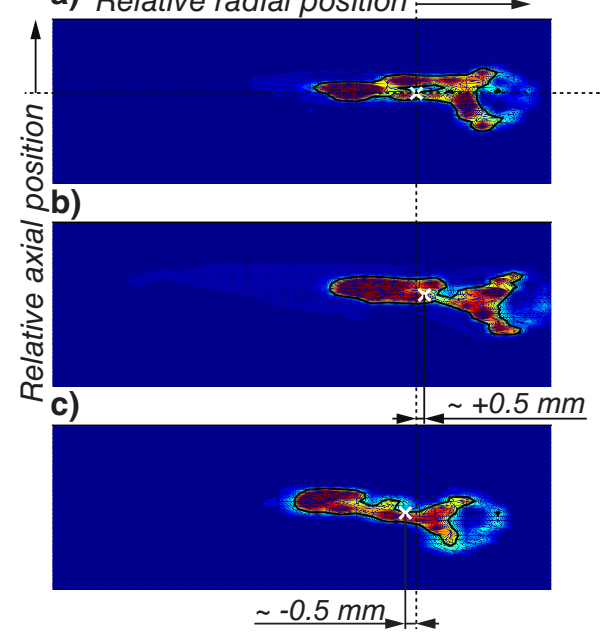

d)
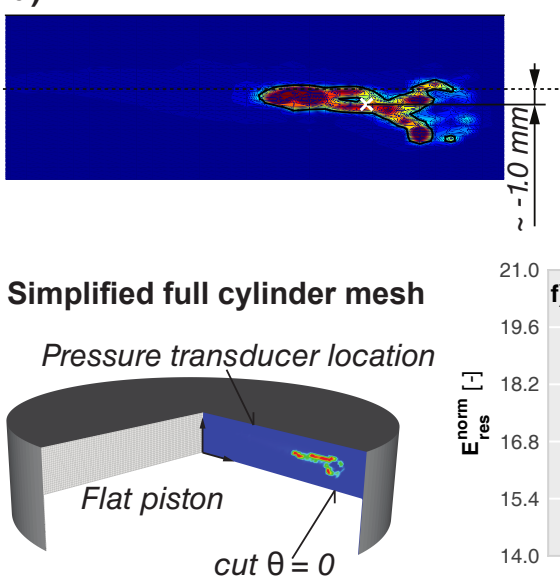

e)

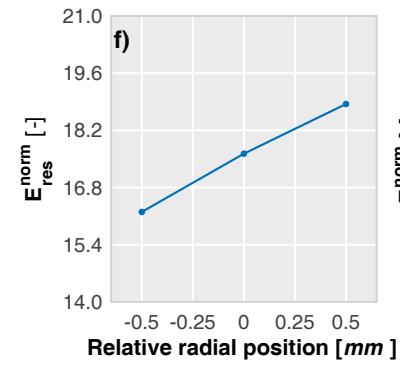

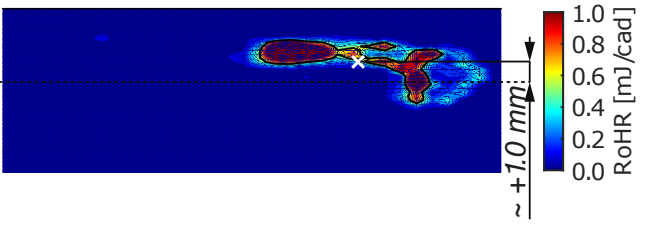

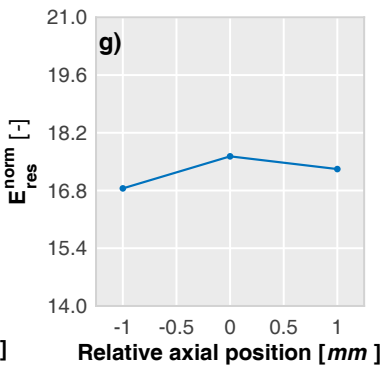

Figure 5: Results of the self-ignition location analysis. a) to e) Snapshots of RoHR contours at the middle spray plane for 3 different radial and axial positions, $f$ ) Differences in the global amplitude of the pressure oscillations along the radial dimension, $g$ ) Differences in the global amplitude of the pressure oscillations along the axial dimension

oscillations $\left(\mathrm{E}_{\mathrm{res}}\right)$. These results confirm the conclusions obtained by Broatch et al [13], that self-ignition location affects to the global amplitude of the pressure oscillations. By contrast, the variation of the $\mathrm{E}_{\text {res }}$ is lower and presents a nearly constant trend when the ignition zone moves along the cylinder axis. Both studies remark the relevance of the injector geometry (number of nozzles, included angle, nozzle diameter, nozzle angle, ...) and spray characterisation (lift-off length, spray length, liquid length, ...) on the resonance phenomenon.

\subsection{Computational domain}

Traditionally, ICE simulations assume the periodic hypothesis to reduce the mesh size and to decrease the calculation time. For example, some authors use sector domains to predict the combustion stability and pollutant emissions in a wide range of operating conditions or engine hardware configurations [39, 40]. Most of these applications are supported by assessing chemical reactions and physical properties of the air-fuel mixture but none of them are based on simulating pressure wave interaction and reflection mechanisms. Hence this study was devised to determine the best domain configuration for reproducing the acoustic field inside the cylinder.

The complete cylinder domain, from now on denoted as Approach 1, was used as a reference, and two additional domains $\left(60^{\circ}\right.$ and $180^{\circ}$ sectors) were build by assuming periodic conditions, identified by Approaches $2 \mathrm{a}$ and $2 \mathrm{~b}$ respectively. In addition, simulations use the same mesh configuration with a base cell size of $3 \mathrm{~mm}$, uniform initial conditions, an injector with 6 nozzles and a time step fixed by a sonic Courant number below one.

According to the spectra shown in Figure 6, the highest dispersion is identified in frequencies between 6 and 8 $\mathrm{kHz}$, while significant differences are also observed in the sec- ond transversal (non-symmetric) mode. This mode is clearly identifiable in Approach 1 whereas it is not noticeable neither in Approach 2a nor in Approach 2b. The third transversal (symmetric) mode is only reproduced by Approaches 1 and 2b. Results show the capability of the sector approaches to reproduce the pressure response at low to medium frequencies, allowing their application for performance or emissions studies in which high frequency effects are negligible. However, a complete cylinder domain with non periodic assumptions must be considered for assessing in-cylinder combustion as a noise source in the cylinder.

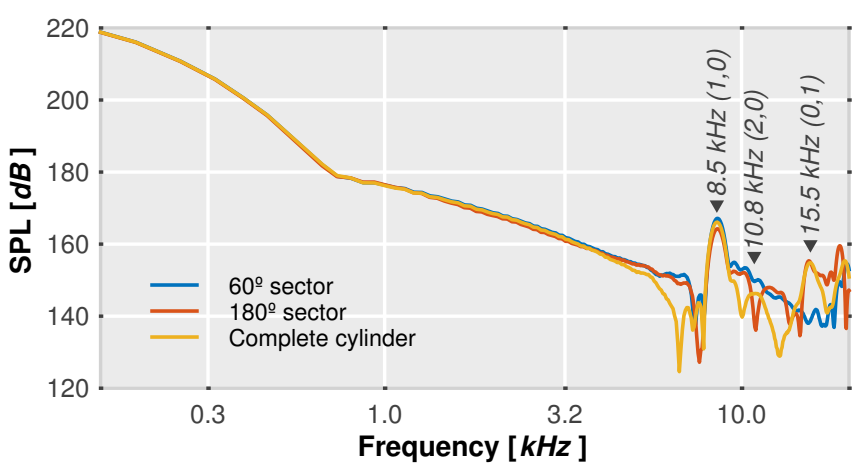

Figure 6: Frequency response of three different computational domains (Approaches 1, 2a and 2b)

\subsection{Definiton of initial conditions}

The last analysis is focused on evaluating the impact of the initial conditions on the prediction of the acoustic source. It compares two closed cycle simulations with a different definition of the initial conditions at IVC. In the first one, termed Approach 3, the initial conditions are taken from a previous gas exchange process (GEP) simulation. It uses the full do- 
main, including intake-exhaust manifolds and valves, to define the flow field at IVC. The second one is the same Approach 1 considered in the previous study. In this case, the initial conditions are spatially averaged from the calculation of the same GEP, keeping the same mean values of species concentration and thermodynamic and turbulence conditions between both simulations.

Figure 7 shows the comparison between both approaches. Here the in-cylinder pressure and the RoHR is plotted against the crank angle degree after Top Dead Centre (cad aTDC). As it can be seen, the time delay is slightly reduced in Approach 3 due to higher local temperatures inside the piston bowl. Consequently, the amount of fuel in reactive conditions is smaller and the maximum value of the RoHR is decreased. This effect causes significant differences in the pressure spectra, especially in the high frequency band. The first two transversal modes (both non-symmetric) are shifted to lower frequencies, its amplitude is enlarged, and the third transversal mode is totally attenuated. However, lower differences are observed in the amplitude of the medium frequency range $(0.6-4 \mathrm{kHz})$. Since it has been demonstrated that the sound pressure level (SPL) of the medium frequency range is directly linked with the maximum pressure timederivative achieved during the combustion [22, 23], the small scatter observed in this frequency span is a direct consequence of the differences in $(\mathrm{d} p / \mathrm{d} t)^{\max }$.

A detailed study of the main physical mechanisms present within the combustion chamber is presented in Fig. 8 in order to identify which are the differences that condition the behaviour of the pressure field. This picture shows two snapshots of the accumulated RoHR contours along the axial dimension of the cylinder at the start of combustion. The crank angle for $10 \%$ of fuel burnt (CA10) was used to determine the beginning of combustion. As commented before, the maximum of RoHR depends on the quantity of fuel in reactive conditions at the start of combustion so that the colour scale achieves higher values in Approach 1. Analysing the location of self-ignition zones, the higher time delay causes deeper spray penetration and the ignitions are brought towards the cylinder walls. The energy release distribution in the combustion chamber reveals a symmetric distribution of both size and location of self-ignition zones in Approach 1 (Figure 8a). By contrast, the energy release presents a random spatial distribution with Approach 3 (Figure 8b).

Moreover, in order to analyse the spray ignition sequence, the combustion chamber was divided into six sectors (one for each injector nozzle), and the RoHR profile was obtained for each one. These profiles were used to estimate the start of the combustion in all sectors by means of the CA10 parameter. Results are presented in a polar graph (Figure 8c) in which the polar axis symbolizes the number of sprays or injector nozzles and the radial axis represents the delay between ignitions (with respect to the first ignition).

Inspecting the sequence of the sprays ignition in Approach 1, it can be observed that they follow a certain symmetry: the sprays located in opposed sides of the chamber have practically the same ignition delay. For instance, sprays 3 and 6
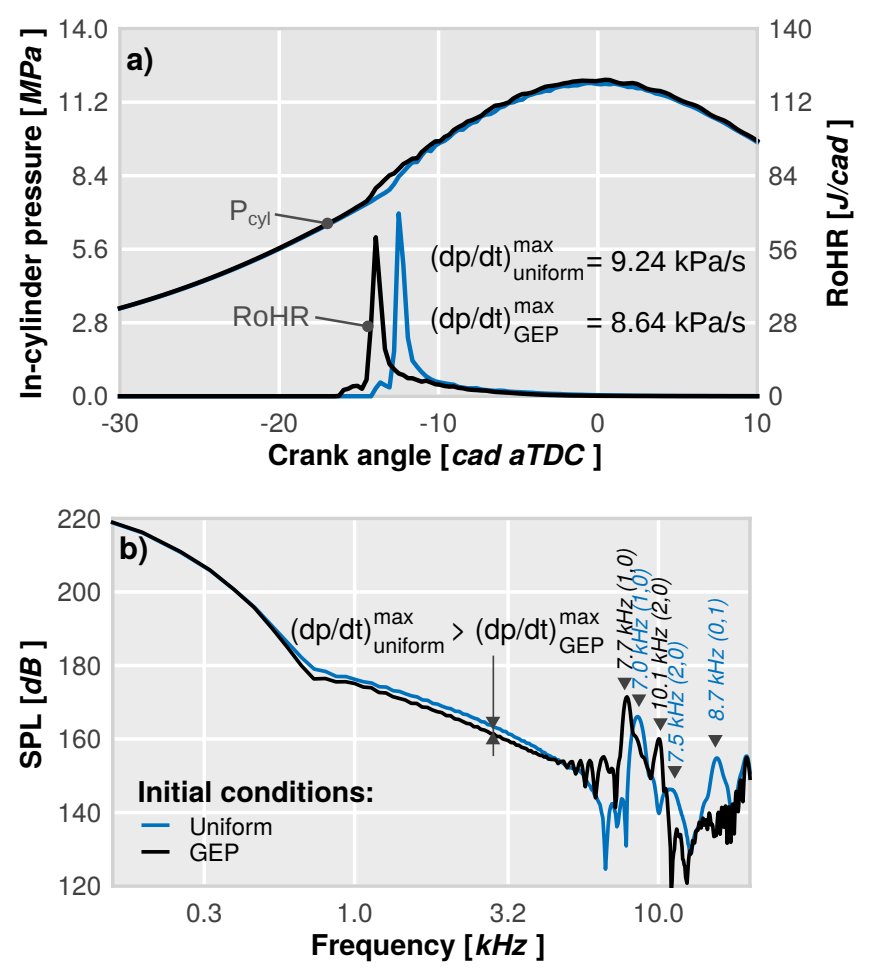

Figure 7: Comparison between Approaches 1 and 3. a) Incylinder pressure and $\mathrm{RoHR}, \mathrm{b})$ Pressure spectra traces

show a delay of $6 \mu$ s respect to the first ignition event whereas the ignition of sprays 2 and 5 is postponed $8 \mu \mathrm{s}$. This singular behaviour is not reproduced by Approach 3, for which the ignitions follow a random timing sequence due to the nonuniform local thermodynamic conditions and species concentration at the start of combustion.

As a summary, the physical mechanisms observed in Approach 3 influence the frequency content of the in-cylinder pressure in a significant way. They are only reproduced by simulating the flow field accurately in terms of thermodynamics, turbulence and species concentration and therefore, it is necessary to calculate the complete engine cycle to asses accurately the acoustic source.

\section{Validation}

The numerical approach obtained as a result of the previous studies, was validated at an operating condition defined by a medium speed (2400 rpm) and a medium load (168 Nm). Usual validation methods compare the in-cylinder pressure profile averaged over a given number of recorded cycles. However, high frequency components of the noise source cannot be assessed with this procedure. For this reason the most representative cycle obtained by means of a statistical study was used as a reference for validation [22]. The instantaneous in-cylinder pressure, registered with a monitor located at the same point as the transducer, is compared with the reference measured cycle in Figure 9a. The maxi- 
a)

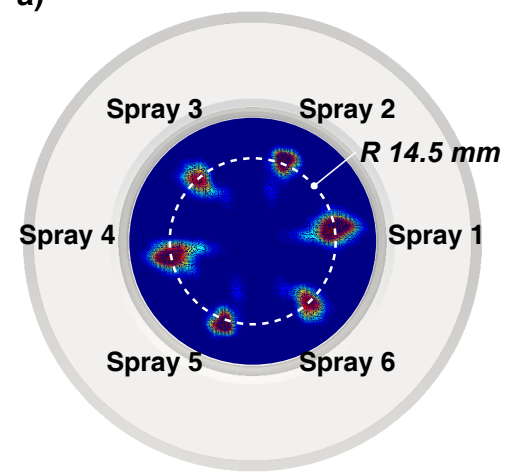

b)

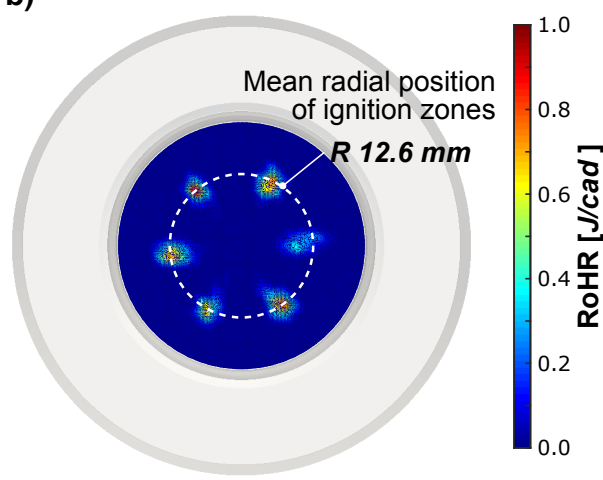

c)

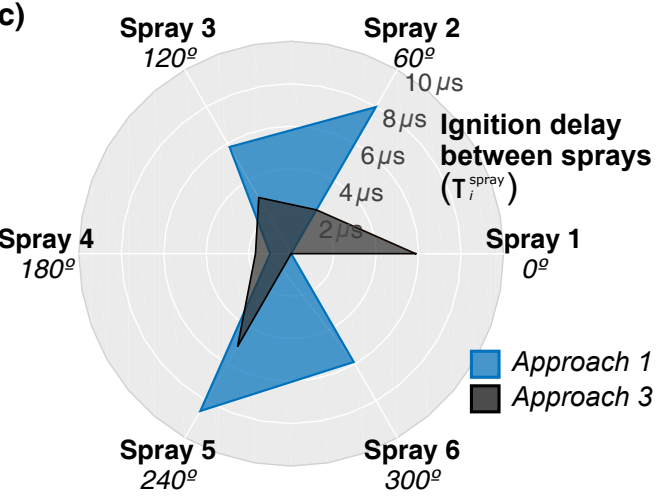

Figure 8: Snapshots of accumulated RoHR contours along the axial dimension of the cylinder engine at the start of combustion. a) Uniform initial conditions simulation (Approach 1), b) Full cycle simulation (Approach 3), c) Auto-ignition delay between sprays

mum relative error $\left(\epsilon_{r}^{\max }\right)$ in terms of in-cylinder pressure between the measurement and the simulation is $6.15 \%$, therefore the pressure evolution is well reproduced by the CFD simulations. RoHR traces present significant differences in the mixing-controlled combustion phase, where the calculation underestimates the heat release rate. In addition, a slight disagreement is observed in the first pilot ignition timing.

In Figure 9b the in-cylinder pressure spectra of all measured cycles are presented together with the simulated spectrum. Focusing on the high frequency range, the amplitude of the first transversal mode $(1,0)$ is well reproduced whereas the second one $(2,0)$ exhibits a slight overestimation. Higher dispersion is observed in the medium to low frequency range $(0.5-2 \mathrm{kHz})$ which can be attributed to the errors in the ignition timing of the first injection.

In view of this, an additional evaluation was performed in order to analyse the impact of this scatter on the external acoustic field. Three common acoustic parameters were considered for this study, CPL, ON and the sound quality of the engine noise (quantified by a mark), all of them detailed in Section 2. They were estimated with the reference measured cycle and also with the CFD model prediction. Table 3 shows that both ON and MARK predictions present deviations smaller than the measurements uncertainty $(<1 \mathrm{~dB})$ and the mark quotation $(<0.5)$, respectively. These values evidence that neither ON nor MARK estimations are affected by the disagreement in spectra at low to medium frequencies, and therefore, no effect is observed on the prediction of metrics related to the external acoustic field.

Table 3: Estimation of the metrics related to external acoustic field

\begin{tabular}{lll}
\hline Parameters & Experiment & CFD \\
\hline CPL $[\mathrm{dB}]$ & 223.9 & 228.6 \\
ON [dB] & 90.34 & 90.86 \\
MARK [-] & 5.66 & 5.23 \\
\hline
\end{tabular}
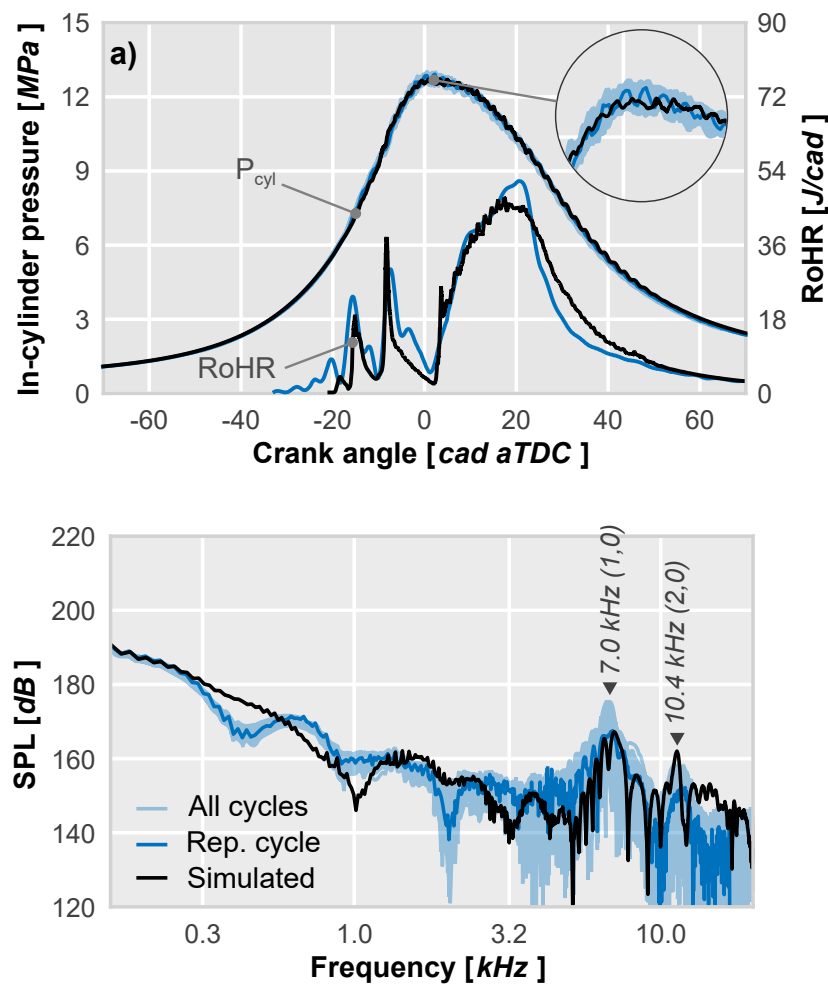

Figure 9: Comparison between measured and CFD calculated. a) In-cylinder pressure and RoHR traces, b) Pressure spectra traces

\section{Conclusions}

The reliability for assessing the combustion process as a source of noise by CFD modelling has been demonstrated in this paper. The implemented model allows to reproduce the behaviour of the in-cylinder pressure in both the time and the frequency domains accurately, and it therefore provides useful information about the physical mechanisms of combustion noise generation. 
In addition, results have shown the relevance of the local flow conditions at the start of combustion for reproducing the in-cylinder acoustic field. Thermodynamic conditions, turbulence and species concentration define both the spatial distribution and the temporal sequence of the self-ignition zones, which are the main cause of the acoustic content of Diesel combustion. These particular conditions are only achievable by simulating the entire engine cycle with the gas exchange process and with the complete cylinder domain. Hence traditional CFD approaches, such as those commonly used for combustion diagnosis or emissions analysis, are not suitable for simulating the noise generation mechanisms properly and they cannot be used for acoustic purposes. Although the model cannot reproduce cycle-to-cycle variations in the incylinder acoustic field owing to its turbulence approach (URANS), results have evidenced enough accuracy to predict thermodynamic conditions and the acoustic field inside the combustion chamber. Therefore, it is reliable for including noise issues as an additional parameter, together with the performance-emissions trade-off traditionally considered, for designing Diesel combustion systems (combustion chamber and injector configuration).

The sonic Courant number plays an important role in the high-frequencies, since the amplitude of the oscillation modes is decreased as it increases. This parameter must be set close to unity during the combustion process in order to ensure that only one cell is swept by a pressure wave between two consecutive time steps of the calculation.

It has been also proved that the global amplitude of the high frequency range in the pressure trace depends on the excitation magnitude (RoHR) and also on the relative position between the self-ignition location and the oscillation nodes (zero amplitude zones).

In summary, the approach presented here can be used to analyse the noise generation mechanisms inside of the combustion chamber. Further analysis is nonetheless needed for a better understanding of the internal acoustic field by applying more elaborated post-processing techniques, such as Proper Orthogonal Decomposition (POD) or Dynamic Mode Decomposition (DMD), in order to identify all relevant phenomena [24]. In addition, the virtual model can be used with different optimization techniques, such as genetic algorithms or full factorial design of experiments, for defining new combustion system designs, with optimal trade-off between consumption and both pollutant and noise emissions $[25,40]$. Finally, further efforts should be undertaken for determining possible benefits of using a more complex turbulence approach (LES) and for extending its application to other combustion concepts [41].

\section{Acknowledgements}

The equipment used in this work has been partially supported by FEDER project funds "Dotación de infraestructuras científico técnicas para el Centro Integral de Mejora Energética y Medioambiental de Sistemas de Transporte (CiMeT), (FEDER-
ICTS-2012-06)", framed in the operational program of unique scientific and technical infrastructure of the Spanish Ministerio de Economía y Competitividad.

J. Gomez-Soriano is partially supported through the "Programa de Apoyo para la Investigación y Desarrollo (PAID)" of Universitat Politècnica de València [grant number FPI-S22016-1353].

The authors want to express their gratitude to CONVERGENT SCIENCE Inc. and Convergent Science GmbH for their kind support for performing the CFD calculations using CONVERGE software.

\section{Bibliography}

[1] B. Masterton, H. Heffner, R. Ravizza, The evolution of human hearing, The Journal of the Acoustical Society of America 45 (4) (1969) 966985. doi: 10.1121/1. 1911574.

[2] S. A. Fausti, D. A. Erickson, R. H. Frey, B. Z. Rappaport, M. A. Schechter, The effects of noise upon human hearing sensitivity from 8000 to $20000 \mathrm{~Hz}$, The Journal of the Acoustical Society of America 69 (5) (1981) 1343-1349.

[3] D. I. Nechaev, A. Y. Supin, Hearing sensitivity to shifts of rippledspectrum patterns, The Journal of the Acoustical Society of America 134 (4) (2013) 2913-2922. doi : 10.1121/1.4820789.

[4] A. Saadu, R. Onyeonwu, E. Ayorinde, A. Ogisi, Road traffic noise survey and analysis of some major urban centers in nigeria, Noise Control Engineering Journal 46 (1998) 146-158. doi:10.12691/ wjee-1-1-2.

[5] H. Liu, J. Zhang, P. Guo, F. Bi, H. Yu, G. Ni, Sound quality prediction for engine-radiated noise, Mechanical Systems and Signal Processing 56-57 (0) (2015) 277-287. doi : 10.1016/j .ymssp. 2014 . 10.005.

[6] C. J. da Silveira Brizon, E. B. Medeiros, Combining subjective and objective assessments to improve acoustic comfort evaluation of motor cars, Applied Acoustics 73 (9) (2012) 913 - 920. doi:10.1016/j. apacoust . 2012.03.013.

[7] F. Flemming, A. Sadiki, J. Janicka, Investigation of combustion noise using a LES/CAA hybrid approach, Proceedings of the Combustion Institute 31 (2) (2007) 3189-3196. doi : 10.1016/j . proci. 2006. 07. 060.

[8] C. F. Silva, M. Leyko, F. Nicoud, S. Moreau, Assessment of combustion noise in a premixed swirled combustor via large-eddy simulation, Computers \& Fluids 78 (2013) 1 - 9, LES of turbulence aeroacoustics and combustion. doi : 10.1016/j . compfluid. 2010.09.034.

[9] K. Ohta, Y. Irie, K. Yamamoto, H. Ishikawa, Piston slap induced noise and vibration of internal combustion engines (1st report, theoretical analysis and simulation), SAE Technical Paper 870990. doi : 10.4271/ 870990.

[10] S. H. Cho, S. T. Ahn, Y. H. Kim, A simple model to estimate the impact force induced by piston slap, Journal of Sound and Vibration 255 (2) (2002) 229-242. doi:10.1006/jsvi.2001.4152.

[11] R. Hickling, D. A. Feldmaier, S. H. Sung, Knock-induced cavity resonances in open chamber Diesel engines, The Journal of the Acoustical Society of America 65 (5) (1979) 1474-1479. doi:10.1121/1. 382910.

[12] L. J. Eriksson, Higher order mode effects in circular ducts and expansion chambers, The Journal of the Acoustical Society of America 68 (2) (1980) 545-550. doi:10.1121/1.384768.

[13] A. Broatch, X. Margot, A. Gil, C. Donayre, Computational study of the sensitivity to ignition characteristics of the resonance in DI diesel engine combustion chambers, Engineering Computations 24 (1) (2007) 77-96. doi : 10. 1108/02644400710718583.

[14] A. J. Torregrosa, A. Broatch, J. Martín, L. Monelletta, Combustion noise level assessment in direct injection diesel engines by means of incylinder pressure components, Measurement Science and Technology 18 (7) (2007) 2131-2142. doi : 10. 1088/0957- 0233/18/7/045. 
[15] F. Payri, A. Broatch, X. Margot, L. Monelletta, Sound quality assessment of diesel combustion noise using in-cylinder pressure components, Measurement Science and Technology 20 (1) (2009) 01-12. doi : 10. 1088/0957-0233/20/1/015107.

[16] A. J. Torregrosa, A. Broatch, X. Margot, V. Marant, Combustion chamber resonances in direct injection automotive Diesel engines: a numerical approach, International Journal of Engine Research 5 (1) (2003) 83-91. doi: 10.1243/146808704772914264.

[17] A. Vressner, A. Lundin, M. Christensen, P. Tunestål, B. Johansson, Pressure Oscillations During Rapid HCCI Combustion, SAE Technical Paper 2003-01-3217. doi : 10.4271/2003-01-3217.

[18] O. Kaario, H. Pokela, L. Kjäldman, J. Tiainen, M. Larmi, LES and RNG turbulence modeling in DI Diesel engines, SAE Technical Paper 200301-1069. doi : 10.4271/2003-01- 1069.

[19] M. Lesieur, O. Métais, P. Comte, Large-Eddy Simulations of Turbulence, Cambridge University Press, 2005. doi : 10 . 1017/CB09780511755507.

[20] S. B. Pope, Ten questions concerning the large-eddy simulation of turbulent flows, New Journal of Physics 6 (1) (2004) 35. doi : 10. 1088/ $1367-2630 / 6 / 1 / 035$.

[21] O. Vermorel, S. Richard, O. Colin, C. Angelberger, A. Benkenida, D. Veynante, Multi-cycle les simulations of flow and combustion in a pfi si 4-valve production engine, in: SAE Technical Paper, SAE International, 2007. doi : 10.4271/2007-01-0151.

[22] A. Broatch, X. Margot, R. Novella, J. Gomez-Soriano, Combustion noise analysis of partially premixed combustion concept using gasoline fuel in a 2-stroke engine, Energy 107 (2016) 612 - 624. doi : 10.1016/j .energy. 2016.04.045.

[23] A. J. Torregrosa, A. Broatch, X. Margot, J. Gomez-Soriano, Towards a Predictive CFD Approach for Assessing Noise in Diesel Compression Ignition Engines. Impact of the Combustion Strategies, International Conference on Modeling and Diagnostics for Advanced Engine systems: the 9th COMODIA, Okayama (Japan).

[24] A. J. Torregrosa, A. Broatch, J. García-Tíscar, J. Gomez-Soriano, Modal decomposition of the unsteady flow field in compression-ignited combustion chambers, Combustion and Flame 188 (2018) 469-482. doi : 10.1016/j . combustflame. 2017.10.007.

[25] A. Broatch, R. Novella, J. Gomez-Soriano, P. Pal, S. Som, Numerical Methodology for Optimization of Compression-Ignited Engines Considering Combustion Noise Control, SAE Technical Paper 2018-010193. doi : 10.4271/2018-01-0193.

[26] F. Ihlenburg, The medium-frequency range in computational acoustics: Practical and numerical aspects, Journal of Computational Acoustics 11 (02) (2003) 175-193. doi : 10.1142/S0218396X03001900.

[27] M. Lapuerta, O. Armas, J. J. Hernández, Diagnosis of DI diesel combustion from in-cylinder pressure signal by estimation of mean thermodynamic properties of the gas, Applied Thermal Engineering 19 (5) (1999) 513-529. doi : 10.1016/S1359-4311(98)00075- 1.

[28] F. Payri, P. Olmeda, J. Martín, A. García, A complete OD thermodynamic predictive model for direct injection diesel engines, Applied Energy 88 (12) (2011) 4632-4641. doi:10.1016/j.apenergy. 2011. 06.005.

[29] F. Payri, A. Broatch, B. Tormos, V. Marant, New methodology for in-cylinder pressure analysis in direct injection diesel engines-application to combustion noise, Measurement Science and Technology 16 (2) (2005) 540-547. doi:10.1088/0957-0233/16/ 2/029.

[30] A. J. Shahlari, C. Hocking, E. Kurtz, J. Ghandhi, Comparison of compression ignition engine noise metrics in low-temperature combustion regimes, Vol. 6, SAE International, 2013, pp. 541-552. doi: 10. 4271/2013-01- 1659 .

[31] M. Wissink, Z. Wang, D. Splitter, A. Shahlari, R. D. Reitz, Investigation of pressure oscillation modes and audible noise in RCCI, HCCI, and CDC, in: SAE Technical Paper, Vol. 2013-01-1652, SAE International, 2013. doi : 10.4271/2013-01- 1652.

[32] V. Yakhot, S. Orszag, Renormalization group analysis of turbulence., Journal of Scientific Computing 1 (1) (1986) 3-51. doi:10.1007/ BF01061452.

[33] C. Angelberger, T. Poinsot, B. Delhay, Improving near-wall combustion and wall heat transfer modeling in si engine computations, in: SAE Technical Paper, SAE International, 1997. doi : 10.4271/972881.
[34] J. K. Dukowicz, A particle-fluid numerical model for liquid sprays, Journal of Computational Physics 35 (2) (1980) 229 - 253. doi: 10.1016/0021-9991(80) 90087-X.

[35] R. D. Reitz, J. C. Beale, Modeling spray atomization with the kelvinhelmholtz/rayleigh-taylor hybrid model, Atomization and Sprays 9 (6) (1999) 623-650.

[36] J. Brakora, R. D. Reitz, A comprehensive combustion model for biodiesel-fueled engine simulations, in: SAE Technical Paper, SAE International, 2013. doi : 10.4271/2013-01-1099.

[37] A. Torregrosa, P. Olmeda, B. Degraeuwe, M. Reyes, A concise wall temperature model for DI diesel engines, Applied Thermal Engineering 26 (11-12) (2006) 1320-1327. doi:10.1016/j.applthermaleng . 2005. 10.021.

[38] Y. Ren, R. B. Randall, B. E. Milton, Influence of the resonant frequency on the control of knock in diesel engines, Proceedings of the Institution of Mechanical Engineers 213 (Part D) (1999) 127-133. doi : 10. 1243/ 0954407991526748.

[39] S. Molina, A. García, J. Pastor, E. Belarte, I. Balloul, Operating range extension of RCCI combustion concept from low to full load in a heavyduty engine, Applied Energy 143 (2015) 211 - 227. doi : 10.1016/j . apenergy . 2015.01.035.

[40] J. Benajes, R. Novella, J. M. Pastor, A. Hernández-López, S. L. Kokjohn, Computational optimization of the combustion system of a heavy duty direct injection diesel engine operating with dimethyl-ether, Fuel 218 (2018) 127-139. doi:10.1016/j . fuel .2018.01.020.

[41] A. Broatch, X. Margot, R. Novella, J. Gomez-Soriano, Impact of the injector design on the combustion noise of gasoline partially premixed combustion in a 2-stroke engine, Applied Thermal Engineering 119 (2017) 530 - 540. doi : 10.1016/j . applthermaleng.2017.03.081.

\section{List of Figures}

1 Computational domains and mesh characterization of the engine architecture . . . . . . .

2 Cross-sectional views and notation of classical acoustic modes in combustion chambers [11].

3 Results of the independence mesh study. a) Comparison of the pressure spectra traces, b) Differences in the global amplitude of the pressure oscillations, c) Computational costs of a single cycle simulation . . . . . . . . . .

4 Results of the time step definition study. a) Comparison of the pressure spectra traces, b) Differences in the global amplitude of the pressure oscillations, c) Computational costs of a single cycle simulation . . . . . . . . . .

5 Results of the self-ignition location analysis. a) to e) Snapshots of RoHR contours at the middle spray plane for 3 different radial and axial positions, f) Differences in the global amplitude of the pressure oscillations along the radial dimension, g) Differences in the global amplitude of the pressure oscillations along the axial dimension . . . . . . . . . . . . 6 Frequency response of three different computational domains (Approaches 1, 2a and 2b) .

7 Comparison between Approaches 1 and 3. a) In-cylinder pressure and RoHR, b) Pressure spectra traces ............... 
8 Snapshots of accumulated RoHR contours along the axial dimension of the cylinder engine at the start of combustion. a) Uniform initial conditions simulation (Approach 1), b) Full cycle simulation (Approach 3), c) Auto-ignition delay between sprays . . . . . . . . . . 10

9 Comparison between measured and CFD calculated. a) In-cylinder pressure and RoHR traces,

b) Pressure spectra traces . . . . . . . . . . 10

\section{List of Tables}

1 Engine and injector specifications ...... 3

2 Parameters definition for studies and validation 6

3 Estimation of the metrics related to external acoustic field ............. 10 